Running head: BC \& MT DEVELOPMENT

\title{
Adapting a Behavioural Coaching Framework for Mental Toughness Development
}

\author{
${ }^{a}$ David R. Anthony*, a Sandy Gordon, ${ }^{\text {b}}$ Daniel F. Gucciardi, and ${ }^{\text {a Brian Dawson }}$ \\ ${ }^{a}$ School of Sport Science, Exercise \& Health, The University of Western Australia \\ ${ }^{\mathrm{b}}$ School of Physiotherapy and Exercise Science, Curtin University
}

\section{Authors' Notes}

Daniel F. Gucciardi is currently supported by a Curtin Research Fellowship. *Address correspondence to David R. Anthony, School of Sport Science, Exercise \& Health, The University of Western Australia, M408, 35 Stirling Hwy, Crawley, WA, Australia, 6009. Email:

dranthony311@gmail.com

Accepted for publication in Journal of Sport Psychology in Action on March $9^{\text {th }} 2017$ 


\begin{abstract}
Mental Toughness (MT) development is an important consideration when seeking to increase and maintain high levels of performance in sport settings. There has been limited research on effective methods to develop MT, and an opportunity exists to incorporate other developmental frameworks in psychology that have shown a positive effect on performance. In this paper, we detail a coach targeted education program aimed at increasing the frequency of desirable mentally tough behaviours (MTb) in elite athletes, which draws on recent work on MTb (e.g., Diment, 2014; Hardy, Bell, \& Beattie, 2014) and an established behavioural coaching model (i.e., GROW, Whitmore, 2002) as the guiding framework. The theoretical foundations of behavioural coaching and relationship with improving performance are briefly discussed. We then describe how we applied the behavioural coaching model in a professional team sport environment during the course of a competitive season, including learning points and future considerations for those practitioners looking to develop MT in sporting contexts.
\end{abstract}

Keywords: Athlete development, coach development, mentally tough behaviour, performance, sport psychology. 


\section{Adapting a Behavioural Coaching Framework for Mental Toughness Development}

The interest in developing mental toughness (MT) in sport has resulted in increased empirical work across different sporting environments (e.g., Bell, Hardy, \& Beattie, 2013; Mahoney, Ntoumanis, Gucciardi, Mallett, \& Stebbings, 2016). Often considered fundamental for high level sporting performance (e.g., Hardy et al., 2014; Jones, Hanton, \& Connaughton, 2007), MT can be defined as "a personal capacity to deliver high performance on a regular basis despite varying degrees of situational demands" (Gucciardi \& Hanton, 2016, p. 442). It is therefore understandable that stakeholders such as coaches, athletes, and/or administrators are interested in programs that can develop MT. In their synthesis of qualitative MT development research, Anthony, Gucciardi, and Gordon (2016) identified that there have been few advancements in understanding what these stakeholders could be doing to elicit MT development.

A recent shift in the MT literature that warrants attention from a cultural perspective, is that earlier work may have reinforced a masculine ideal that gave sporting organisations permission to push their athletes with less concern for athlete health and well-being (Tibbert, Andersen, \& Morris, 2015). Exploring such socio-cultural issues is an important extension to the literature, and pertinent when considering the process of developing MT in organisations where success is expected. However, there is an increasing focus on maintaining athlete well-being as a means by which to maintain performance in the current climate (e.g., Pink, Saunders, \& Stynes, 2015), and expectations from stakeholders reflect this cultural shift (Fletcher \& Streeter, 2016). Therefore, frameworks such as Bandura's (2001) social cognitive theory emphasise the value of athletes developing an accurate understanding of the behavioural expectations within their environments as a means to facilitate individual and organisational performance and satisfaction. Accordingly, there is a need to explore frameworks from other established domains of psychological practice that might provide opportunities for advancing our current understanding of the MT development field (see also Mahoney, Ntoumanis, Mallett, \& 
Gucciardi, 2014). Given recent work on mentally tough behaviours (MTb; e.g., Diment, 2014; Gucciardi, Jackson, Hanton, \& Reid, 2015; Hardy et al., 2014), we believe a behavioural coaching framework has the potential to shed light on understanding those behavioural expectations and processes that may foster the development of MT. We also believe that, as a unique concept, MTb is best conceptualised as the conduit through which MT can influence performance. In other words, a focus on working with observable behaviours can complement the traditional focus on targeting unobservable psychological resources that underpin MT. Therefore, the purpose of this article is to introduce a coach targeted education program aimed at increasing the frequency of desirable MTb in athletes, using an established behavioural coaching model as the guiding framework.

\section{Theoretical Foundations of Behavioural Coaching}

Behavioural coaching originated from the field of behaviourism (Passmore, 2007a), which is considered one of the formative fields in psychology. Behaviourism focuses on the actions people display that enhance the likelihood of bringing about desired outcomes in certain contexts (Bandura, 1969; Skinner, 1953), in contrast to the internal influences that cannot be seen. Scholarly interest in behaviourism dates back to Pavlov's experiments into conditioned responses early in the 20th century (Wolpe \& Plaud, 1997), with the proposition that dogs (and potentially humans) could be trained to respond reflexively, or without conscious thought to certain stimuli, spawning research into the associations between behaviour and punishment or reward. Skinner's (1953) classical and operant conditioning research extended this foundational work. He distinguished between respondent behaviour, which followed on from Pavlov's model where an individual learns to respond a certain way to an existing event, and operant behaviour, whereby an individual actively attempts a new behaviour that is reinforced by a successful outcome (Passmore, 2007a). This work was followed up by Bandura's (1969) argument that early behaviourism theories did not account sufficiently for the human capacity for abstract thinking, and the influence of beliefs, values, and memories on one's behaviour. He explained 
this capacity through social learning theory, whereby an individual learns from observing others' behaviours and the associated outcomes, and the concept of self-efficacy, which is based on an individual's perception of their ability to perform a certain task. More recently, Hayes, Strosahl, and Wilson (1999) offered a different perspective on the links between thoughts, emotions and behaviour, whereby the avoidance of internal processes may result in problematic behaviours. They proposed the Acceptance and Commitment Therapy (or ACT) framework as a more unified model for behaviour change. Research guided by behaviourism has provided a foundation to assist in the scientific development of psychological models and techniques (Michie, Richardson, et al., 2013) that have been applied across many situations and environments (Eldridge \& Dembkowski, 2012). Thus, behaviourism is deeply entrenched within the psychological sciences.

We have seen the development of different behavioural coaching frameworks, with increasingly frequent applications in organisational and leadership development settings (Lai \& McDowall, 2014). Behavioural coaching is defined as "a structured, process-driven relationship between a trained professional coach and an individual or team ... to help coaches develop competencies and remove blocks to achieve valuable and sustainable changes in their professional and personal lives" (Skiffington \& Zeus, 2003, p. 6). The key concepts underpinning the process include reinforcement, modelling, stimulus control, rehearsal, and goal-setting (Eldridge \& Dembkowski, 2012), which share some similarities with more traditional counselling approaches across different domains of psychology (e.g., clinical, sport). For example, Poczwardowski, Sherman, and Ravizza (2004) highlighted the similarities between sport psychology approaches and the integration of cognitivism and behaviourism, or more traditional counselling, although did not provide detail about how such theories could be applied in sport settings. Acknowledging these similarities, one of the major differences is that behavioural coaching approaches are focused on the actions that can be seen or heard by others, as opposed to the focus on those unobservable cognitions that underpin behaviour in counselling 
approaches (e.g., cognitive behavioural therapy). An overview of other key differences is depicted in Table 1.

Further consideration of these differences highlights the value of behavioural coaching in an environment where performance improvement is key, particularly when the goal is to improve interaction and coaching skills of those involved to elicit behaviour change in others. Previous research supports this assertion, with coaching approaches contributing to visible increases in desirable skills or behaviours (Stokes, Luiselli, \& Reed, 2010; Theeboom, Beersma, \& van Vianen, 2014), improvements in well-being (Grant, Green, \& Rynsaardt, 2010), coping (Moen \& Skaalvik, 2009), and motivation (Spence \& Grant, 2007) in groups of coachees; factors that are considered important for maintaining performance in high pressure environments such as elite sport (Gould, Dieffenbach, \& Moffett, 2002). However, as with any approach to psychological practice, there are advantages and disadvantages of behavioural coaching that can influence its effectiveness across different situations; an overview is provided in Table 2.

\section{Behavioural Coaching and Improving Performance}

The integration of behaviourism and cognitivism is a common therapeutic approach adopted by sport psychologists (Poczwardowski et al., 2004), yet there is currently limited research regarding the use of established behavioural coaching frameworks in sport settings. However, there are similarities in the underlying components across sporting and more traditional coaching domains (e.g., leadership development). The psychological skills often identified as best practice for improving and maintaining high levels of athletic performance, such as visualisation, arousal management, and goal-setting (Macnamara \& Collins, 2013), are also considered the foundation of behavioural coaching (e.g., rehearsal, stimulus control, and goal-setting; Luiselli, 2012). Furthermore, the implementation strategies for behavioural coaching approaches share similarities with other sport psychology approaches (e.g., Arnold \& Sarkar, 2015; Poczwardowski et al., 2004). It would therefore be expected that a behavioural coaching approach found to have a positive effect on performance in organisational and 
leadership development settings (e.g., Lai \& McDowall, 2014), could also be modified for use to improve performance in sport settings (e.g., Wagstaff, Fletcher, \& Hanton, 2012).

Although behaviourism can encompass a broad range of factors relating to sport performance from a psychological perspective, of particular interest is how it relates to the concept of MT development in high performance settings. Further consideration of goal attainment provides a link to recent research in sport, specifically targeting both performance and MT. In their paper exploring MTb, Hardy et al. (2014) proposed that MT can be defined as an "ability to achieve personal goals in the face of pressure from a wide range of different stressors" (p. 70). Their definition provides an overt connection to behaviourism, in that MTb is required to achieve personal goals in competitive performance situations, regardless of the cognitions, attitudes, and emotions at play. Applying the same conceptual foundation in their research with elite youth cricketers, Bell et al. (2013) found that defining, discussing, and agreeing on the most desirable behaviours with coaches and athletes resulted in an increase in both MT and competitive performance statistics when compared to a control group.

Aligned with these theoretical and empirical considerations, we applied a behavioural coaching framework as a part of coach development initiative to assist in developing MT in athletes in a professional team sport environment. Whitmore's (2002) GROW model has been identified as the most widely used behavioural coaching model (Eldridge \& Dembkowski, 2012); an overview of the four stages of the GROW coaching model is provided in Table 3 . The GROW model is also based on the premise that the coachee is an active participant in, and responsible for, influencing the behaviour of others to improve collective performance (Whitmore, 2009), highlighting its value for coaches in team sport environments. Importantly, from a translational standpoint, the uncomplicated nature of the GROW model makes it suitable for coachees with limited psychological training (Passmore, 2007b) who operate in an environment involving a number of competing demands and limited time for reflection. 
Primarily as a result of these factors, it was decided that this model would be the most appropriate for our application.

\section{A Coach-Targeted Program to Increase Mentally Tough Behaviours}

Access to the team sport environment was granted due to the organisation's interest in exploring MT development as a means by which to improve athlete and team performance. We first interviewed experienced informants (i.e., coaches, sport scientists, administrators, and athletes) to explore their perspectives of MTb within this team sport environment. The process identified a collection of desirable behaviours that were observed consistently in athletes considered mentally tough. Using these findings, and recommendations for specifying clear concept definitions (Podsakoff, MacKenzie, \& Podsakoff, 2016), we defined MTb as $a$ purposeful yet adaptable verbal or physical act that contributes positively to performance through the attainment and progression of self-referenced objectives or goals.

The aim of the program was to increase the frequency of desirable MTb that aligned with the team's core values (see Table 4 for some example behaviours from the program). The sample consisted of early career professional team sport athletes engaged at the highest possible level of competition over the course of their competitive season. The participants included three development coaches between 31 and 33 years of age, with two to five years elite coaching experience, and 15 professional team sport athletes, with ages ranging from 18 to 23 years $(M=$ $19.95, S D=1.28)$. All participants were contracted to a national level team who play in both the national and state level competitions (depending on weekly team selections).

\section{Practitioner Philosophy}

At the time of delivering this program, the lead author was a registered psychologist working towards his endorsement in sport and exercise psychology and his doctorate of philosophy $(\mathrm{PhD})$ in Australia, having accrued 10 years' applied experience as a psychologist across organisational, sporting, and clinical domains. The lead author's coaching philosophy towards the development, improvement, and maintenance of high performance draws upon 
strength-based approaches (e.g., Linley \& Joseph, 2004), with an emphasis on understanding and operationalising positive observable behaviours that best represent psychological skills, and how they can be adapted across multiple contexts.

\section{Program Design}

Whitmore's (2002) GROW coaching model formed the theoretical foundations of the program, offering a framework to guide the behavioural coaching dialogue. The aim was to improve both the frequency of desirable MTb and overall performance. It was designed to include aspects of reinforcement, modelling, stimulus control, rehearsal and goal-setting; factors identified as key behavioural coaching concepts by Eldridge and Dembkowski (2012). The program involved two phases over a five month period from late pre-season (early February) to just after the mid-point of the competition season (early July). Activities included an initial information workshop and monthly structured group workshops with the coaches, as well as observation of various events that formed part of the regular athlete training and development program in four-week blocks. The typical structure of each block and the corresponding phase detailed in Table 5.

\section{Phase 1: Developing an understanding of the environment, the coaches, and the} athletes. Following approval of the program structure from the sporting organisation, Phase 1 began with an initial workshop with the coaches to provide an overview of the project and the program (see Table 6 for an overview of the workshop content). The first four-week block involved observation of the coaches operating across the different settings within the organisation, engagement in informal discussions to draw on their level of knowledge, and general questioning of coaches and support staff to better understand the organisational factors and the operational constraints that may influence program delivery. The primary goals were to: a) become familiar with the athletes and coaches involved, specifically each coach's interpersonal style (Gray, 2006), experience, and insight into and knowledge of behavioural frameworks (cf. Peterson, 2006), to develop an understanding of how to tailor individual 
interactions to suit the coach (Arnold \& Sarkar, 2015); b) develop rapport and positive working relationships (Giges, Petitpas, \& Vernacchia, 2004), including a mutually beneficial working alliance (Bordin, 1994); and c) increase both coach and athlete perception of the lead author as a member of the organisation (Sharp \& Hodge, 2013), often achieved by consistent presence in sessions, at training, and around the club (Birrer, Wetzel, Schmid, \& Morgan, 2012). Although these goals were relevant throughout the program, Phase 1 concluded with the second coaching group workshop (refer to Table 6 for an overview).

Phase 2: Applying the behavioural coaching framework. With a focus on developing the coaches' ability to understand and apply the behavioural coaching framework, Phase 2 included subsequent four-week blocks that targeted a different collection of the desirable MTb. It involved two parts: a) three structured coaching group workshops targeting subsets of MTb; and b) ['On-the-job'/live] behavioural coaching with each coach.

Phase 2a: Structured coaching group workshops. Workshops three to five followed a similar interactive structure consistent with the 4-steps of Whitmore's (2002) GROW model, which aimed to increase awareness and responsibility in coaches. The Phase 2 workshops were designed to employ the GROW model to target a subset of the desirable MTb, with the subset nominated by the club's head of development (refer to Table 6 for additional detail of the workshop content). It was envisaged that the practice of using the GROW model and a two page workbook (included as supplementary material) would reinforce the process-driven approach to behaviour change that coaches were encouraged to use to frame their interactions with athletes. An example of the application of the GROW model from a workshop is provided in Table 3.

Phase 2b: 'On-the-job' behavioural coaching and other activities. This part of Phase 2 included observation of one-on-one (coach-athlete) game reviews and game preparation meetings, as well as training drills, training review sessions, athlete development sessions, early career group meetings, and team meetings facilitated by the coaches involved in the program. Interactions and feedback with each coach were structured to align with the GROW model and 
key behavioural coaching concepts identified previously, with the process designed to draw attention to the pertinent information that had been discussed during the group workshops. Furthermore, part of the feedback process following these activities involved prompting the coaches to engage in self-reflection, to develop their own processes (Hay, 2007), and rehearse the strategies they were encouraged to employ with athletes.

One method of applying the GROW model is provided within the context of one-on-one game reviews. In this activity, coaches were encouraged to utilise stages of the model as a framework to promote questioning and collectively agree on the short-term development opportunities for specific behaviours with the athlete of interest. Noting that this process did not use the GROW model in its entirety on some occasions, the coaching process can be employed to progress a task that has been discussed before, and as such, a session can begin at any stage (Whitmore, 2009). In the midst of the competition season in a modern day professional team sport environment, it is rare that athletes are unaware of their individualised development goals, and what the reality of their level of performance was during the most recent game. As a result, the observed reviews usually started with an overview of the strengths and areas for improvement from the game (Reality). However, for consistency of application, an example from the athlete reviews that included all four stages of the GROW model is provided in Table 3. It should be noted that this process can be compared to aspects of other developmental theories, such as self-determination theory (SDT; for a review see, Deci \& Ryan, 2000), specifically when promoting the athletes' perceived competence in their ability to improve.

Coaches were adept at identifying what needed to change, or what an athlete needed to work on to improve certain areas throughout the program. What was often missing, likely due to perceived time constraints, was the process of coaches working with an athlete to identify and clarify one or two specific focus points to work on over the coming week. From an SDT perspective (Deci \& Ryan, 2000), the athlete therefore lacked clarity, choice and ownership on how he was going to improve in the desired area, with the coaches' initial tendency being to 
adopt more controlling coach behaviours, such as telling the athlete what he was required to do (Bartholomew, Ntoumanis, Ryan, \& Thogersen-Ntoumani, 2011). Previous research has highlighted the importance of autonomy-supportive coaching behaviours (e.g., perceived choice) to increase the likelihood of positive behaviour change in athletes (Su \& Reeve, 2011).

Furthermore, research by Bell et al. (2013) identified that the likelihood of desirable behaviour change is increased when athletes and coaches spend time collaborating on a way forward (for a comparison in organisational settings, see also, Bluckert, 2005; Whitmore, 2009). There was also a tendency for the coach to not follow up with an athlete during the week to enquire on his progress with the agreed weekly focus points, check understanding, or to remind him of an upcoming opportunity to work on the identified areas during training sessions (i.e., reinforcement). As a result, one of the real-time goals of the intervention related to encouraging the coaches' dialogue to move from telling (or controlling), to a more regular process throughout the week that increased the perceptions of athlete choice during conversations to expedite behaviour change.

When observing the coaches' interactions with the athletes during training or specific developmental drills, the practitioner's primary aim was to again move the conversations from controlling (i.e., telling athletes) to more autonomy-supportive where possible. The coaches were encouraged to use reflective questioning with athletes, such as "what was one thing you did in that drill that was done well?" or "what was one thing that you could improve on, and how would you improve?" Aligning with the concepts of modelling and reinforcement, this process replicated the strategies the coaches were asked to use when reflecting on their performance following one-on-one reviews (e.g., the "good, better, how" approach). Hay (2007) identified that using such prompts as a means to reflect enhances an individual's capability to change and respond more effectively to similar situations in the future, and to promote critical thinking and autonomy in changing behaviour. There were two supplementary aims: first, to promote brief and effective follow-up of the athlete's focus points from the one-on-one review for that week; 
and second, to draw on real-time learning opportunities with each coach to reinforce his competence with the process (e.g., unmediated learning situations, Werthner \& Trudel, 2006). This strategy was also important in the context of stimulus control, using the opportunity for the coach to relate the stimulus to his or the athlete's behaviour in real time, and make a change, as opposed to advising the coach of it at a later time when the learning opportunity might be less evident.

\section{Program Evaluation}

The effectiveness of the program was evaluated using a number of processes. First, data collection included coaches rating athletes with a bespoke nine-item Mentally Tough Behaviour Scale $(\mathrm{MTbS})$ that was created following qualitative interviews with coaches, support staff, and athletes and aligned with the team's core values. This scale required coaches to rate how frequently they observed the athlete in question display each of the behaviours when the opportunity arose over the past four-weeks using a 7-point Likert rating scale (e.g., "Effort levels during training remain consistently high, whether preparing for a normal or high pressure match"; $1=$ never, $4=$ half of the time, $7=$ always). Ratings were completed via an online survey site and collected every 4 weeks during the program period. Data collection also included two initial baseline ratings, and two post-intervention ratings to explore the maintenance effects of the program. On average, following baseline, the raw data showed an increase in the MTbS scores through the first half of the program period, at which point they plateaued. Following the completion of the program in July, MTbS scores decreased marginally until the end of the season.

Second, in an attempt to check social validation (e.g., Barker et al., 2011), the coaches were asked to provide comments at the conclusion of each workshop, using similar methods to those described previously (e.g., a "good, better, and how" for the workshop, or from the past four weeks). At the conclusion of the program, the coaches were also asked to provide comments on what aspects of the program they thought were most and least useful, and 
suggestions on how to improve the program. Generally, the comments highlighted some of the more useful aspects of the program from the coaches' perspectives, and areas to advance its effectiveness in the future. As an example, Coach A stated: “...[the BC model was] great to work with.... it has definitely assisted me in becoming a much improved coach.” Another comment from Coach B related more to logistical factors relating to the provision of feedback following observations of sessions (e.g., “... [consider need to] provide direct feedback immediately post review meetings when we are time poor. If there is no time to give feedback to development coach then an email will suffice." On the topic of applying the model during his reviews, Coach C identified: “The concept of summarizing 'how' we are going to develop the key areas out of their [the athlete's] review has been beneficial." This inclusion of regular feedback allowed for some formal evaluation of the process, and to maintain the integrity of the program. Notably, outside of these comments, the observations towards the end of the program indicated that the coaches were able to apply the framework more efficiently, with less guidance from the lead author following the observed activities.

\section{Learning Points}

There were a number of learning points during the program, with two primary learning points warranting further discussion. The first related to developing a level of flexibility as a result of the regularly changing schedules, and relying on the coaches to keep the lead author informed of these changes. It was observed that these coaches, as the most junior coaches in the organisation, were often at the mercy of most aspects of the team program, and regularly had to revise or reschedule sessions and reviews to fit with changes made by more senior members of the organisation. After arriving at the organisation in the early stages expecting a specific activity and finding that it had been rescheduled, or was no longer occurring, the value of open and regular communication with the coaches was emphasised. To the coaches' credit, when this concern was raised by the lead author, the coaches were proactive in maintaining regular contact 
and providing frequent updates on timing changes to ensure the lead author had every opportunity to attend the prescribed sessions.

Second, it would be remiss to give the impression that coaches implemented the framework from the very start of the program. Although the coaches maintained a willingness to learn and an interest in the program itself, they were, like the athletes, operating in an environment where they would receive large amounts of information from a number of stakeholders (e.g., senior coaches, sport scientists, analysts). With the challenges in changing coach communication strategies (e.g., from telling to promoting athlete choice) and interpersonal style having been reported elsewhere (e.g., Mahoney et al., 2016), it was important to look for additional opportunities to reinforce the process. Therefore, the education process for coaches to incorporate this framework required both verbal and written feedback from the lead author following the activities. It also included making use of opportunities to prompt the coaches to engage in reflective practice, in an attempt to expedite their understanding and application.

Interactions between the lead author and the coaches also provided opportunities to model and reinforce other parts of the GROW framework. As an example, the lead author suspected that initial attempts to keep feedback from reviews informal in the coaches' open-plan office did not allow some of the coaches an opportunity to engage due to a range of distractions. Upon raising the issue (e.g., the 'reality'), the coaches and lead author openly discussed options for a way forward. Subsequently, the identification of brief periods in less distracting locations (e.g., meeting room, off-site cafe) would allow them to better engage in the process. Importantly for the lead author, maintaining a receptive and collaborative approach in these situations provided opportunities to progressively work on increasing the effectiveness of the program.

\section{Developing MT from a Behavioural Framework}

In the previous section we provided insight into how we adapted a behavioural coaching framework to develop MT in professional male team sport athletes. First, we must acknowledge that our methodology may appear to deviate from the traditional use of a behavioural coaching 
model in which the coach (i.e., the lead author) works with a coachee (i.e., team coaching staff) to change their behaviour. Although our goal was to increase the frequency of MTb in the athletes via the development coaches, we believe that our application of the model fits with the definition of behavioural coaching provided earlier and the structure of Whitmore's (2002) GROW model. Specifically, retaining this structure throughout the program as a means to teach the coaches to adapt their coaching behaviour (e.g., “...develop competencies and achieve change..."; Skiffington \& Zeus, 2003, p. 6), achieved our goal of behaviour change in athletes. Although this approach may be a novel interpretation of how to use behavioural coaching, we believe that it offers increased opportunity for development of coaches and athletes alike in professional sporting settings.

Consistent with acceptance based behavioural therapies (ABBT; Gardner \& Moore, 2010; Hayes et al., 2012), the benefit of encouraging an individual to 'just do' something, or perform a desired action/behaviour/skill, regardless of the thoughts that may be occurring, can provide a novel way to approach MT development in fast paced and information rich professional environments. In these situations the focus shifts from what might require significant time and expertise to combat negative or problematic thought processes that may adversely affect performance, to something more realistic in a pressure situation. If athletes know and understand how to display the behaviours that have been identified, promoted, and reinforced as important to both their own and their team performance (cf. Bandura, 2001), it provides an opportunity to free them up to display those desirable behaviours. Therefore, developing awareness in athletes to behave in certain ways in response to certain stimuli, coupled with coaches working closely with athletes during training, competition, and elsewhere to clarify such behaviour holds promise in the area of MT development. It also provides support for behaviour based programs (e.g., Bell et al., 2013) being more effective than focussing on the development of MT attributes, which have traditionally been the emphasis of MT development research (Anthony et al., 2016; Connaughton, Thelwell, \& Hanton, 2011). 
We acknowledge that exclusively goal-directed behavioural approaches, such as those that reduce complex behaviour to mechanistic stimulus-response chains are unlikely to succeed (Peterson, 2006), when attempting to achieve sustained behavioural change. Human behaviour flows from a combination of events (e.g., affective, cognitive, behavioural, and spiritual; Peterson, 2006), and the whole person must be addressed in the process of prolonged behavioural change. We are therefore not attempting to dismiss the importance of foundational approaches in psychology, such as the ABC (Activating event - Belief - Consequences) model of Cognitive Behavioural Therapy, but suspect that a behavioural intervention will in turn affect an individual's cognitions and feelings, just not in the traditional linear manner.

\section{Conclusion}

The behavioural approach to MT development discussed in this article offers an alternative framework to previous attempts focused on any range of MT attributes. As Hardy et al. (2014) identified, MTb needs to occur before we consider the influence of cognitions, attitudes and emotions. In professional sporting environments where the execution of those desirable skills/behaviours (or MTb) are most important, with limited time available to invest in changing antecedent factors (e.g., cognitions), focussing on what can be seen, trained, and evaluated may be a more logical approach when looking to enhance performance and improve consistency. Previous research has provided support for the utility and effectiveness of behavioural coaching (e.g., Bell et al., 2013; Lai \& McDowall, 2014; Theeboom et al., 2014), which can identify, define and target those desirable behaviours observed regularly in high performers, and increase their frequency across larger groups. Overall, when seeking to make positive change in sporting organisations that have a number of stakeholders and limited opportunities, we encourage the decision makers to consider the behavioural coaching approach as a viable option. 


\section{References}

Adams, M. (2016). Coaching psychology: An approach to practice for educational psychologists. Educational Psychology in Practice, 1-14. doi: 10.1080/02667363.2016.1152460

Anthony, D. R., Gucciardi, D. F., \& Gordon, S. (2016). A meta-study of qualitative research on mental toughness development. International Review of Sport and Exercise Psychology, 9, 160-190. doi: 10.1080/1750984X.2016.1146787

Arnold, R., \& Sarkar, M. (2015). Preparing athletes and teams for the Olympic Games: Experiences and lessons learned from the world's best sport psychologists. International Journal of Sport and Exercise Psychology, 13, 4-20. doi:

10.1080/1612197X.2014.932827

Bandura, A. (1969). Social-learning theory of identificatory processes. In D. A. Goslin (Ed.), Handbook of socialization theory and research (pp. 213-262). Chicago: Rand McNally.

Bandura, A. (2001). Social cognitive theory: An agentic perspective. Annual Review of Psychology, 52, 1-26. doi: 10.1146/annurev.psych.52.1.1

Bartholomew, K. J., Ntoumanis, N., Ryan, R. M., \& Thogersen-Ntoumani, C. (2011). Psychological need thwarting in the sport context: Assessing the darker side of athletic experience. Journal of Sport \& Exercise Psychology, 33, 75-102.

Bell, J. J., Hardy, L., \& Beattie, S. (2013). Enhancing mental toughness and performance under pressure in elite young cricketers: A 2-year longitudinal intervention. Sport, Exercise, and Performance Psychology, 2, 281-297. doi: 10.1037/a0033129

Birrer, D., Wetzel, J., Schmid, J., \& Morgan, G. (2012). Analysis of sport psychology consultancy at three Olympic Games: Facts and figures. Psychology of Sport and Exercise, 13, 702-710. doi: 10.1016/j.psychsport.2012.04.008

Bluckert, P. (2005). The similarities and differences between coaching and therapy. Industrial and Commercial Training, 37, 91-96. doi: 10.1108/00197850510584241

Bordin, E. S. (1994). Theory and research on the therapeutic working alliance: New directions. In A. O. Horvath \& L. S. Greenberg (Eds.), The working alliance: Theory, research, and practice (pp. 13-37). New York: Wiley.

Bronfenbrenner, U. (1999). Environments in developmental perspective: Theoretical and operational models. In S. L. Friedmann \& T. D. Wachs (Eds.), Measuring environments across life span: Emerging methods and concepts (pp. 3-28). Washington DC: American Psychological Association.

Connaughton, D., Thelwell, R., \& Hanton, S. (2011). Mental toughness development: Issues, practical implications and future directions. In D. F. Gucciardi \& S. Gordon (Eds.), 
Mental toughness in sport: Developments in research and theory (pp. 136-162).

Abingdon, Oxon: Routledge.

Deci, E. L., \& Ryan, R. M. (2000). The" what" and" why" of goal pursuits: Human needs and the self-determination of behavior. Psychological inquiry, 11, 227-268.

Diment, G. M. (2014). Mental toughness in soccer: A behavioral analysis. Journal of Sport Behavior, 37, 317-332.

Eldridge, F., \& Dembkowski, S. (2012). Behavioral coaching. In J. Passmore, D. B. Peterson, \& T. Freire (Eds.), The Wiley-Blackwell handbook of the psychology of coaching and mentoring (pp. 298-318). Oxford, UK: John Wiley \& Sons.

Fletcher, D., \& Streeter, A. (2016). A case study analysis of a high performance environment in elite swimming. Journal of Change Management, 16, 123-141. doi: $10.1080 / 14697017.2015 .1128470$

Giges, B., Petitpas, A. J., \& Vernacchia, R. A. (2004). Helping coaches meet their own needs: Challenges for the sport psychology consultant. Sport Psychologist, 18, 430-444.

Gould, D., Dieffenbach, K., \& Moffett, A. (2002). Psychological characteristics and their development in Olympic champions. Journal of Applied Sport Psychology, 14, 172-204. doi: 10.1080/10413200290103482

Grant, A. M., Green, L., \& Rynsaardt, J. (2010). Developmental coaching for high school teachers: Executive coaching goes to school. Consulting Psychology Journal: Practice and Research, 62, 151-168. doi: 10.1037/a0019212

Gray, D. E. (2006). Executive coaching: Towards a dynamic alliance of psychotherapy and transformative learning processes. Management Learning, 37, 475-497. doi: $10.1177 / 1350507606070221$

Gucciardi, D. F., \& Hanton, S. (2016). Mental toughness: Critical reflections and future considerations. In R. Schinke, K. McGannon, \& B. Smith (Eds.), The Routledge international handbook of sport psychology (pp. 439-448). New York, NY: Routledge.

Gucciardi, D. F., Jackson, B., Hanton, S., \& Reid, M. (2015). Motivational correlates of mentally tough behaviours in tennis. Journal of Science and Medicine in Sport, 18, 67-71. doi: http://dx.doi.org/10.1016/j.jsams.2013.11.009

Hardy, L., Bell, J., \& Beattie, S. (2014). A neuropsychological model of mentally tough behavior. Journal of Personality, 82, 69-81. doi: 10.1111/jopy.12034

Hay, J. (2007). Reflective practice and supervision for coaches. Maidenhead, England: Open University Press.

Jones, G., Hanton, S., \& Connaughton, D. (2007). A framework of mental toughness in the world's best performers. Sport Psychologist, 21, 243-264. 
Lai, Y.-L., \& McDowall, A. (2014). A systematic review (SR) of coaching psychology:

Focusing on the attributes of effective coaching psychologists. International Coaching Psychology Review, 9, 118-134.

Linley, P. A., \& Joseph, S. (2004). Positive psychology in practice. Hoboken, NJ: John Wiley \& Sons.

Luiselli, J. K. (2012). Behavioral sport psychology consulting: A review of some practice concerns and recommendations. Journal of Sport Psychology in Action, 3, 41-51. doi: $10.1080 / 21520704.2011 .653048$

Macnamara, A., \& Collins, D. (2013). Do mental skills make champions? Examining the discriminant function of the psychological characteristics of developing excellence questionnaire. Journal of Sports Sciences, 31, 736-744. doi:

$10.1080 / 02640414.2012 .747692$

Mahoney, J. W., Ntoumanis, N., Gucciardi, D. F., Mallett, C. J., \& Stebbings, J. (2016). Implementing an autonomy-supportive intervention to develop mental toughness in adolescent rowers. Journal of Applied Sport Psychology, 28, 199-215. doi: 10.1080/10413200.2015.1101030

Mahoney, J. W., Ntoumanis, N., Mallett, C. J., \& Gucciardi, D. F. (2014). The motivational antecedents of the development of mental toughness: A self-determination theory perspective. International Review of Sport and Exercise Psychology, 7, 184-197. doi: 10.1080/1750984X.2014.925951

Michie, S., Richardson, M., Johnston, M., Abraham, C., Francis, J., Hardeman, W., . . Wood, C. E. (2013). The behavior change technique taxonomy (v1) of 93 hierarchically clustered techniques: building an international consensus for the reporting of behavior change interventions. Annals of behavioral medicine, 46, 81-95. doi: 10.1007/s12160-013-94866

Michie, S., West, R., \& Spring, B. (2013). Moving from theory to practice and back in social and health psychology. Health Psychology, 32, 581-585. doi: 10.1037/a0030205

Moen, F., \& Skaalvik, E. (2009). The effect from executive coaching on performance psychology. International Journal of Evidence Based Coaching and Mentoring, 7, 31-49.

Passmore, J. (2007a). Behavioural coaching. In S. Palmer \& A. Whybrow (Eds.), The handbook of coaching psychology (pp. 73-85). East Sussex: Routledge.

Passmore, J. (2007b). An integrative model for executive coaching. Consulting Psychology Journal: Practice and Research, 59, 68-78. doi: 10.1037/1065-9293.59.1.68

Peterson, D. B. (2006). People are complex and the world is messy: A behavior-based approach to executive coaching. In D. R. Stober \& A. M. Grant (Eds.), Evidence based coaching 
handbook: Putting best practices to work with your clients. (pp. 51-76). Hoboken, NJ: Wiley.

Pink, M., Saunders, J., \& Stynes, J. (2015). Reconciling the maintenance of on-field success with off-field player development: A case study of a club culture within the Australian Football League. Psychology of Sport and Exercise, 21, 98-108. doi: http://dx.doi.org/10.1016/j.psychsport.2014.11.009

Poczwardowski, A., Sherman, C. P., \& Ravizza, K. (2004). Professional philosophy in the sport psychology service delivery: Building on theory and practice. Sport Psychologist, 18, 445-463.

Podsakoff, P. M., MacKenzie, S. B., \& Podsakoff, N. P. (2016). Recommendations for creating better concept definitions in the organizational, behavioral, and social sciences. Organizational Research Methods, 19, 159-203. doi: 10.1177/1094428115624965

Sharp, L.-A., \& Hodge, K. (2013). Effective sport psychology consulting relationships: Two coach case studies. Sport Psychologist, 27, 313-324.

Skiffington, S., \& Zeus, P. (2003). Behavioral coaching: How to build sustainable personal and organizational strength. North Ryde, NSW, Australia: McGraw-Hill.

Skinner, B. F. (1953). Science and human behavior. New York: Macmillan.

Spence, G. B., \& Grant, A. M. (2007). Professional and peer life coaching and the enhancement of goal striving and well-being: An exploratory study. The Journal of Positive Psychology, 2, 185-194. doi: 10.1080/17439760701228896

Stokes, J. V., Luiselli, J. K., \& Reed, D. D. (2010). Behavioral intervention for teaching tackling skills to high school football athletes. Journal of Applied Behavior Analysis, 43, 509-512.

Su, Y.-L., \& Reeve, J. (2011). A meta-analysis of the effectiveness of intervention programs designed to support autonomy. Educational Psychology Review, 23, 159-188. doi: 10.1007/s10648-010-9142-7

Theeboom, T., Beersma, B., \& van Vianen, A. E. M. (2014). Does coaching work? A metaanalysis on the effects of coaching on individual level outcomes in an organizational context. The Journal of Positive Psychology, 9, 1-18. doi: 10.1080/17439760.2013.837499

Tibbert, S. J., Andersen, M. B., \& Morris, T. (2015). What a difference a "Mentally Toughening" year makes: The acculturation of a rookie. Psychology of Sport and Exercise, 17, 68-78. doi: 10.1016/j.psychsport.2014.10.007

Wagstaff, C. R. D., Fletcher, D., \& Hanton, S. (2012). Positive organizational psychology in sport. International Review of Sport and Exercise Psychology, 5, 87-103. doi: 
Werthner, P., \& Trudel, P. (2006). A new theoretical perspective for understanding how coaches learn to coach. Sport Psychologist, 20, 198-212.

Whitmore, J. (2002). Coaching for performance: Growing people, performance and purpose (3rd ed.). London: Nicholas Brealey Publishing.

Whitmore, J. (2009). Coaching for performance: Growing human potential and purpose (4th ed.). Boston, MA: Nicholas Brealey Publishing. 
Table 1: Coaching versus counselling approaches to behaviour change (Bluckert, 2005).

\begin{tabular}{ll}
\hline Coaching Approach & Counselling Approach \\
\hline $\begin{array}{l}\text { Solution-focussed to achieve present and future work- } \\
\text { related behaviour change. }\end{array}$ & $\begin{array}{l}\text { Emotion-focussed to explore problematic emotional } \\
\text { states, personal history and the effect these factors may } \\
\text { have on functioning. }\end{array}$ \\
\hline $\begin{array}{l}\text { Initial aim is to improve performance through } \\
\text { behaviour change. }\end{array}$ & Initial aim to modify problematic thoughts. \\
\hline $\begin{array}{l}\text { More frequently conducted with a higher functioning } \\
\text { client group. }\end{array}$ & $\begin{array}{l}\text { Client group is more often the clinical and sub-clinical } \\
\text { pathological population. }\end{array}$ \\
\hline $\begin{array}{l}\text { Utilises performance feedback from a range of } \\
\text { stakeholders (e.g., supervisor, peers, and/or } \\
\text { customers). }\end{array}$ & $\begin{array}{l}\text { Draws primarily on client's experiences and self- } \\
\text { reports. }\end{array}$ \\
\hline $\begin{array}{l}\text { Less frequent sessions, and less concern regarding } \\
\text { confidentiality allows for various locations for } \\
\text { sessions. }\end{array}$ & $\begin{array}{l}\text { Often 50-60 minute sessions once weekly initially, } \\
\text { with increased confidentiality requiring that sessions } \\
\text { occur in the therapists consulting room. }\end{array}$ \\
\hline
\end{tabular}

Table 2: Advantages and disadvantages of behavioural coaching (Adams, 2016; Bluckert, 2005; Spence \& Grant, 2007; Whitmore, 2002).

\begin{tabular}{ll}
\hline Advantages & Disadvantages \\
\hline $\begin{array}{l}\text { Provides a structured approach to the intervention } \\
\text { process, often with guidelines for application. }\end{array}$ & $\begin{array}{l}\text { Requirement to evaluate own capabilities as a coach in } \\
\text { new situations. }\end{array}$ \\
\hline $\begin{array}{l}\text { Solution-focussed approach enhances more targeted } \\
\text { coaching skills when limited interaction opportunities } \\
\text { exist (e.g., time poor high performance environments). }\end{array}$ & $\begin{array}{l}\text { Solution-focussed approach sometimes not appropriate } \\
\text { for mental ill-health/illness; requires referral to a } \\
\text { clinical expert before coaching can proceed. }\end{array}$ \\
\hline $\begin{array}{l}\text { Increased opportunities to promote the collective } \\
\text { understanding of organisational values amongst } \\
\text { employees. }\end{array}$ & $\begin{array}{l}\text { Conflict between coachee values and organisational } \\
\text { values results in low likelihood of success and lasting } \\
\text { change. }\end{array}$ \\
\hline $\begin{array}{l}\text { Increased insight into desirable organisational } \\
\text { behaviours, and how to better align coachee } \\
\text { behaviours. }\end{array}$ & $\begin{array}{l}\text { Inaccurate understanding of the organisational } \\
\text { behaviours by coach can result in difficulty } \\
\text { operationalising desirable behaviours with a coachee. }\end{array}$ \\
\hline $\begin{array}{l}\text { As external to the organisation, coach has separation } \\
\text { from any emotional ties and a more objective view of } \\
\text { situation. }\end{array}$ & $\begin{array}{l}\text { Inaccurate assessment of situation as an external } \\
\text { provider will prevent 'buy-in' from coachee and } \\
\text { decrease likelihood of success. }\end{array}$ \\
\hline
\end{tabular}


Table 3: The four stages of the GROW coaching model (Whitmore, 2002), and examples from current program.

\begin{tabular}{|c|c|c|c|c|}
\hline Stage & Description/Task & Example Questions & Structured workshop example & One-on-one review example \\
\hline Goal & $\begin{array}{l}\text { Setting goals for the session or, } \\
\text { more specifically, identifying } \\
\text { what the desired outcome is } \\
\text { for the coaching session. }\end{array}$ & $\begin{array}{l}\text { - What would you like to walk } \\
\text { away from this session with? } \\
\text { - What would you like to have } \\
\text { achieved at the conclusion of this } \\
\text { session? }\end{array}$ & $\begin{array}{l}\text { Strategies to increase the frequency of } \\
\text { athletes using their strengths in games }\end{array}$ & $\begin{array}{l}\text { Increasing an athlete's speed of ball } \\
\text { disposal during contests with opposition } \\
\text { athletes (previously identified as an } \\
\text { ongoing area for development by coaching } \\
\text { staff). }\end{array}$ \\
\hline Reality & $\begin{array}{l}\text { To explore the current situation } \\
\text { for the coachee, or reality } \\
\text { checking. The aim is to } \\
\text { identify what the start point is } \\
\text { in terms of changing } \\
\text { behaviour. }\end{array}$ & $\begin{array}{l}\text { - How has your behaviour } \\
\text { changed since our last } \\
\text { session/review? } \\
\text { - What has been problematic? } \\
\text { - How would you rate your current } \\
\text { level of performance in this area } \\
\text { on a scale of } 1 \text { to } 5 \text { ? } \\
\text { - What is one thing that has been } \\
\text { good about the change? What is } \\
\text { one thing that could be better? }\end{array}$ & $\begin{array}{l}\text { Average level of performance on a five } \\
\text { point Likert scale to identify the reality. } \\
\text { Note: This second step was used to } \\
\text { promote thought about who in the athlete } \\
\text { group is performing well and who requires } \\
\text { more assistance. It also encouraged } \\
\text { coaches to think about what they might be } \\
\text { currently doing to be assisting with (or } \\
\text { potentially impeding) athlete development } \\
\text { in the area of interest, to link in to the } \\
\text { Options stage. }\end{array}$ & $\begin{array}{l}\text { Athlete had difficulty gaining possession of } \\
\text { the ball cleanly (i.e., picking it up on his } \\
\text { first attempt) when under pressure, which } \\
\text { subsequently slowed how quickly he was } \\
\text { able to pass it to a teammate. } \\
\text { Athlete identified that he was not } \\
\text { committing the necessary time to these } \\
\text { developmental training drills due to a lack } \\
\text { of understanding how it would benefit him }\end{array}$ \\
\hline Options & $\begin{array}{l}\text { Identify and explore the various } \\
\text { strategies or courses of action, } \\
\text { or what can someone do, or } \\
\text { how can they take steps } \\
\text { towards the desired change. }\end{array}$ & $\begin{array}{l}\text { - Considering what could be } \\
\text { better, how do you think you } \\
\text { could improve your behaviour? } \\
\text { - What have you done in the past } \\
\text { that has worked well? } \\
\text { - What have you observed others } \\
\text { doing that has influenced their } \\
\text { performance? How could you } \\
\text { apply what you've observed to } \\
\text { your own situation? }\end{array}$ & $\begin{array}{l}\text { A two-step process: } \\
\text { 1) Identification \& discussion of senior } \\
\text { athletes that were considered an exemplar } \\
\text { or role model for regularly displaying } \\
\text { strengths. } \\
\text { 2) Identification and discussion of what } \\
\text { these senior athletes were observed doing } \\
\text { around the club, during training and } \\
\text { meetings, or outside of formal sessions that } \\
\text { attributed to their ability to display their } \\
\text { strengths more regularly in games. } \\
\text { Note: This two-step process allowed the } \\
\text { coaches an opportunity to draw on their } \\
\text { collective knowledge to identify and } \\
\text { operationalise the behaviour of interest } \\
\text { from a developmental perspective. }\end{array}$ & $\begin{array}{l}\text { Coach showed video footage of some } \\
\text { occasions when the athlete had gained } \\
\text { clean possession as a means to increase } \\
\text { athlete's perception of ability to change, as } \\
\text { well as training and game video footage of } \\
\text { a senior teammate (i.e., reinforcement and } \\
\text { modelling), providing a link between the } \\
\text { drill and game performance. } \\
\text { Discussion covered areas the athlete could } \\
\text { target in the coming week, specifically } \\
\text { what are the options to increase the } \\
\text { frequency of this desired behaviour in the } \\
\text { training schedule (i.e., developmental } \\
\text { training drills). }\end{array}$ \\
\hline
\end{tabular}




\begin{tabular}{|c|c|c|c|c|}
\hline Stage & Description/Task & Example Questions & Structured workshop example & One-on-one review example \\
\hline $\begin{array}{l}\text { Way } \\
\text { Forward }\end{array}$ & $\begin{array}{l}\text { "What is to be done, When, by } \\
\text { Whom, and the Will to do it" } \\
\text { (Whitmore, 2009, p.55), or } \\
\text { identification of the way } \\
\text { forward; the practical take- } \\
\text { away points that one can } \\
\text { implement to build on and } \\
\text { achieve the desired goal. }\end{array}$ & $\begin{array}{l}\text { - What exactly will you do? When } \\
\text { will you do it? With whom? } \\
\text { - What makes this change } \\
\text { important to you? } \\
\text { - What might get in the way (such } \\
\text { as personal barriers, events and } \\
\text { other people)? }\end{array}$ & $\begin{array}{l}\text { Identification of the agreed focus areas to } \\
\text { increase the frequency of athletes } \\
\text { displaying their respective strengths. } \\
\text { Each coach (Whom) would continue to } \\
\text { schedule and facilitate the specialist } \\
\text { training drills (What) following training } \\
\text { sessions a minimum of once weekly } \\
\text { (When) that targeted each of their athletes' } \\
\text { individual strengths. Coach Will to } \\
\text { undertake these tasks was inherent in their } \\
\text { role, but enhanced by their } \\
\text { acknowledgement of the value of playing } \\
\text { to strengths for developing athletes. }\end{array}$ & $\begin{array}{l}\text { Athlete \& coach collaboratively identify } \\
\text { the Way forward. This process included } \\
\text { discussing and agreeing on When the } \\
\text { athlete will be able to work on this } \\
\text { behaviour (e.g., specific parts of the } \\
\text { training sessions), What will be involved } \\
\text { (e.g., specific developmental drill), with } \\
\text { Whom (e.g., which coach will facilitate it, } \\
\text { and which teammate they must work with), } \\
\text { and the likely outcome of the athlete's } \\
\text { application (e.g., "working on this skill } \\
\text { during this training drill should increase the } \\
\text { effectiveness of your decision making } \\
\text { under pressure during games") to further } \\
\text { increase Will. }\end{array}$ \\
\hline
\end{tabular}


Table 4: Examples of targeted mentally tough behaviours by category.

\section{Category
(Core Value)}

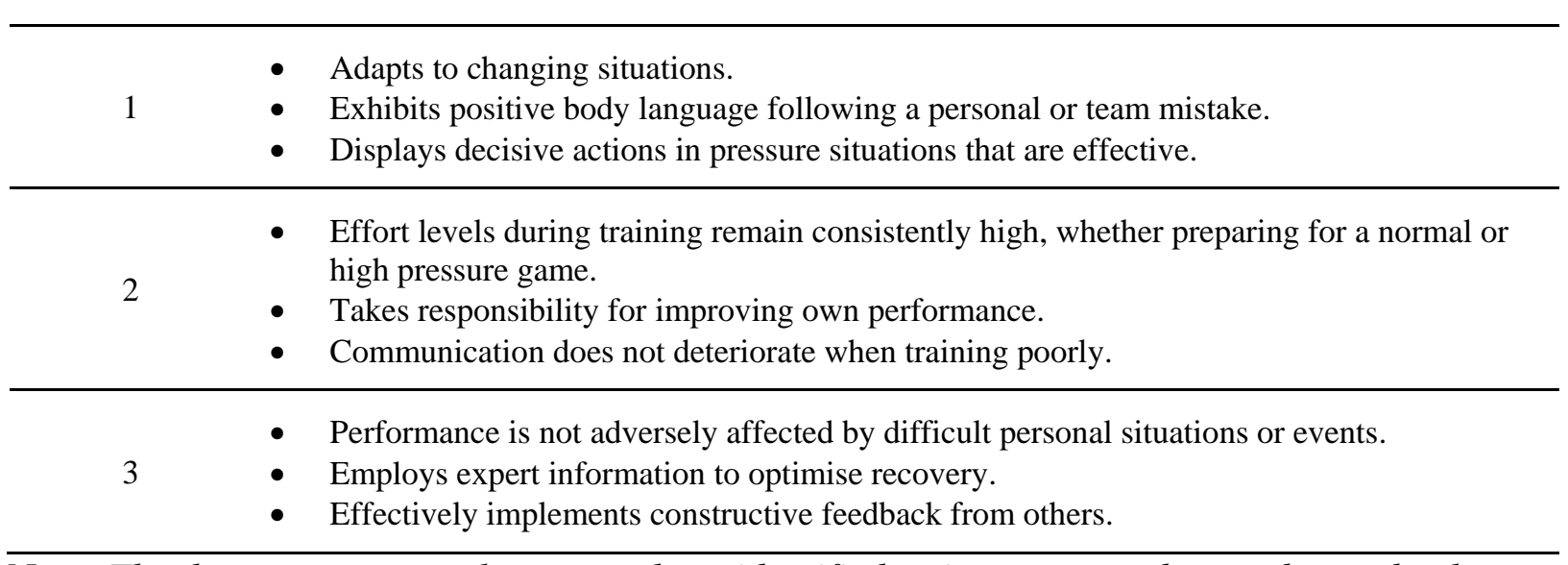

Note: The three core team values were those identified as important and agreed upon by the team at the beginning of the season, with category labels omitted at the request of the sporting organisation. 
Table 5: Typical four-week block of the behavioural coaching program.

\begin{tabular}{|c|c|c|c|}
\hline Week & Event & Activities & Process/Outcome \\
\hline 1 & $\begin{array}{l}\text { Structured coaching group } \\
\text { workshop. }\end{array}$ & $\begin{array}{l}\text { - } 60 \text { minute session. } \\
\text { - Brief review of previous four week block. } \\
\text { - Completion of two page GROW workbook (see } \\
\text { supplementary material). }\end{array}$ & $\begin{array}{l}\text { - Identification of focus points for the group of athletes } \\
\text { for the next four weeks. } \\
\text { - Modelling the GROW framework to highlight the utility } \\
\text { of the model for coach-athlete interactions. }\end{array}$ \\
\hline 2 & Coach A observation. & $\begin{array}{l}\text { Observation of one-on-one (coach-athlete) game reviews } \\
\text { and game preparation meetings, training drills, training } \\
\text { review sessions, athlete development sessions, early career } \\
\text { group meetings, and team meetings. } \\
\text { - Information collected from interactions and observations to } \\
\text { use as examples in the formal four-weekly workshops. }\end{array}$ & $\begin{array}{l}\text { - Provision of verbal "in the moment" feedback when } \\
\text { possible, verbal feedback at the completion of a session, } \\
\text { as well as written feedback in the form of a summary } \\
\text { regarding the observations and learning points at the } \\
\text { conclusion of each week of observation. } \\
\text { - Modelling the skills they were encouraged to use with } \\
\text { the athletes during interactions (e.g., asking coaches to } \\
\text { reflect on their own performance using the "good, } \\
\text { better, and how" framework.). } \\
\text { - Use of context-relevant applied examples from } \\
\text { observations to ensure discussion points were relevant } \\
\text { to the coaches, and to increase coach 'buy-in' to } \\
\text { process. }\end{array}$ \\
\hline
\end{tabular}

3 Coach B observation.

As per Week 2.

As per Week 2. 
Table 6: Structured coaching group workshop outlines.

\begin{tabular}{|c|c|c|c|}
\hline $\begin{array}{l}\text { Phase / } \\
\text { Workshop }\end{array}$ & Content & Processes \& Tools & Goals \\
\hline $1 / 1$ & $\begin{array}{l}\text { - Overview of the structure of the } \\
\text { behavioural coaching program: } \\
\text { a) Behaviour focus aligned with team } \\
\text { values; } \\
\text { b) Those parties involved; } \\
\text { c) Facilitator (lead author) role, including } \\
\text { most desirable sessions to attend; } \\
\text { d) Coaches' role; } \\
\text { e) Athletes' role; } \\
\text { f) Anticipated outcome of increased } \\
\text { consistency and level of athlete } \\
\text { gerformance. } \\
\text { g) Evaluation and feedback. }\end{array}$ & $\begin{array}{l}\text { - Open two-way dialogue. } \\
\text { - Prompting discussion on how to best maintain } \\
\text { communication between facilitator and coaches } \\
\text { throughout project. } \\
\text { - Summary handout for coaches. }\end{array}$ & $\begin{array}{l}\text { - Introduce self. } \\
\text { - Emphasise value of this type of program for } \\
\text { coach and athlete development. } \\
\text { - Provide opportunities to increase perceived } \\
\text { choice. } \\
\text { - Increase likelihood of coaches 'buying-in' to } \\
\text { program. }\end{array}$ \\
\hline
\end{tabular}

- Overview of the GROW framework and its relationship with performance.

- Overview of how the framework will be facilitated, including practical examples across each prescribed activity (e.g. coaching group workshops, one-on-one game reviews etc).

- Ideas for the type of feedback that coaches could expect (e.g., verbal and written) and when to expect it.

- Coach role in the process - importance of feedback to facilitator to improve product.
- Open two-way dialogue.

- Structure workshop to follow GROW model (e.g., Goals of today's workshop, What is the Reality in terms of where we are at in the program currently, discussion of the Options for different parts of the program, and what is the Way Forward from this workshop.)

- Encouraging suggestions on how the coaches can best receive feedback.

- Review of two page GROW workbook (available online as supplementary material) that will be used in future workshops.

- Summary handout for coaches, maintaining GROW format.
- Increase coach familiarity with GROW model and utility across different settings.

- Highlight value of the framework to help guide interactions and provide tangible take away focus points for athletes.

- Continue to look for opportunities to promote coach choice and increase buy in. 


\begin{tabular}{|c|c|c|c|}
\hline $\begin{array}{l}\text { Phase / } \\
\text { Workshop }\end{array}$ & Content & Processes \& Tools & Goals \\
\hline $2 / 3-5$ & $\begin{array}{l}\text { - Brief overview of GROW framework and } \\
\text { specific MTb target area (Category 1, 2, or } \\
\text { 3, as per Table 4). } \\
\text { - Work through two page GROW workbook. }\end{array}$ & $\begin{array}{l}\text { - Open two-way dialogue. } \\
\text { - Structure of workshop to follow GROW model. } \\
\text { - Two page GROW workbook. } \\
\text { - Facilitate discussion and draw on coaches' varying } \\
\text { knowledge and experience (i.e., different positional } \\
\text { focus of defence, attack or midfield for each coach) to } \\
\text { complete workbook, using their answers to promote } \\
\text { discussion. } \\
\text { - Summary handout for coaches, maintaining GROW } \\
\text { format. }\end{array}$ & $\begin{array}{l}\text { - Focus on application over theory. } \\
\text { - Increase opportunities for coach self- } \\
\text { reflection, and increased professional } \\
\text { development as a result of vicarious learning } \\
\text { (cf. Werthner \& Trudel, 2006). } \\
\text { - Provide opportunities for coaches to } \\
\text { collaborate on which MTb's will be targeted } \\
\text { following workshops, to increase their } \\
\text { likelihood of action (cf. Michie, West, \& } \\
\text { Spring, 2013). } \\
\text { - Clear, actionable, and realistic focus points for } \\
\text { the subsequent four week block. }\end{array}$ \\
\hline
\end{tabular}




\section{Supplementary Material}

Mentally Tough behaviour development - worksheet (category $x$ )

1. REALITY: In the table below, identify how often you observe your athletes displaying the following mentally tough behaviours $(M T b)$ when they should $(1=$ Never, $3=$ Half the time, $5=$ Always).

\begin{tabular}{l|l|l|l}
\hline & $(M T b \# 1)$ & $(M T b \# 2)$ & $(M T b \# 3)$ \\
\hline $\begin{array}{l}\text { Rating } \\
\text { (/5) }\end{array}$ & & & \\
\hline
\end{tabular}

2. OPTIONS: Who is a good senior role model for each of these MTb's?

$\circ$ What are one or two of the actions/activities/training drills that this athlete does well to develop and display these behaviours?

\begin{tabular}{l|l|l|l}
\hline & $($ MTb \#1) & $($ MTb \#2) & $($ MTb \#3) \\
\hline \begin{tabular}{l|l} 
Role \\
Model
\end{tabular} & & & \\
\hline & & & \\
e.g. \\
action 1
\end{tabular}

NB: Consider the specific actions/activities/training drills that you have observed that you could show \& explain to your athletes \& encourage them to do more regularly 
3. OPTIONS: For each of these MTb's, identify one activity/drill/strategy that:

- Has been $\boldsymbol{G O O D / w o r k i n g ? ~}$

- You could do BETTER/improve on?

○ $H O W$ could you do it better?

\begin{tabular}{l|l|l|l}
\hline & $($ MTb \#1) & $($ MTb \#2) & (MTb \#3) \\
\hline GOOD & & & \\
BETTER & & & \\
\hline HOW & & & \\
\hline
\end{tabular}

4. WAY FORWARD: What are our agreed focus areas for the next four weeks for each of these MTb's?

- What is one strategy we will continue to $d o, \&$ one strategy we will aim to do better to increase the frequency of these mentally tough behaviours in your athletes?

\begin{tabular}{l|l|l|l}
\hline & $($ MTb \#1) & $($ MTb \#2) & (MTb \#3) \\
\hline $\begin{array}{c}\text { continue } \\
\text { to do }\end{array}$ & & & \\
\hline do better & & & \\
& & & \\
& & & \\
\hline
\end{tabular}

